\title{
CARBON NANOTUBES AND NANO ZINC FERRITES: A NOBLE COMBINATION TO ENHANCE BIOMASS AND LENGTH OF SORGHUM BICOLOR
}

Dhirendra Kumar Tiwari ${ }^{1}$, Javier Villegas ${ }^{2}$, Ana Velia Coria-Tellez ${ }^{3}$, César Adrián Limón Luna ${ }^{4}$, Dhananjay Tripathi ${ }^{5}$ and Prakhar Sengar ${ }^{6}$

${ }^{1}$ CONACYT, Michoacan de Ocampo, Mexico, ${ }^{2}$ IIQB-UMSNH, Michoacan de Ocampo, Mexico, ${ }^{3}$ Laboratorio de Análisis y Diagnóstico del Patrimonio, El Colegio de Michoacán,, Michoacan de Ocampo, Mexico, ${ }^{4}$ Universidad Politécnica de Pénjamo, Pénjamo, Guanajuato, México, Guanajuato, Mexico, ${ }^{5}$ ICMR- National Institute for Research in Environmental Health (NIREH) Bhopal, India, India, ${ }^{6}$ Centro de Nanociencias y Nanotecnología $(\mathrm{CNyN})$, Universidad Nacional Autónoma de México (UNAM), Ensenada, Mexico, Ensenada, Baja California, Mexico

Abstract: This study represents use of organic and inorganic engineered nanoparticles for crop production. The study has been performed on sorghum bicolor plant which is considered to be important staple in semi-arid and arid countries. The result shows that synthesized nanomaterials can be used as plant growth promoter and fertilizer, which can bring an innovation in agricultural industry for biomass gain, fruit and bioenergy production.

Key words: Carbon nanotubes (CNTs), Nano-agriculture, Plant growth promoter, Sorghum bicolor L., Nano Zinc-ferrites (NZF).

Introduction: Application of nanotechnology in the field of biology has demonstrated immense progress and potential. Currently, integration of nanotechnology with modern agricultural practices has helped in innovating new techniques such as precision farming [1,2]. Carbon nanotubes (CNTs) role in enhancing plant growth is well studied [3]. In our previous study, it has been reported that at low concentration Multiwalled carbon nanotubes (MWCNTs), were able to penetrate the seed coat of the maize [4]. The interaction of MWCNTs with maize seed led to partial dismemberment, resulting in high porosity which enhanced the uptake of water, nutrients and oxygen. Higher uptake of nutrients is associated with the increased biomass of the maize seedling. The results suggested the utilization of MWCNTs for improving the crop production in the arid and semi-arid zone.

Micronutrients like manganese, copper, boron, iron, molybdenum, zinc etc. play an important role in the growth and development of plants. The formulation consisting of micronutrients are given to plants to improve the productivity. Various nanoparticles have been tested to provide appropriate level of micronutrients in plants.

The modern nanotechnology-based tools and techniques have the potential to address the various problems of conventional agriculture and can revolutionize this sector. These tools have a great and promising future for the modern agriculture practices like precision delivery of nutrients and fertilizers, disease diagnosis at an early stage and enhanced crop production.

Materials and Methods: The acquired materials; Bacteriological agar (BA) Bioxon® and MWCNT ( $>95 \%$ purity), $\left.\mathrm{Zn}\left(\mathrm{NO}_{3}\right)_{2} \cdot 6 \mathrm{H}_{2} \mathrm{O}(98 \%), \mathrm{Fe}\left(\mathrm{NO}_{3}\right)_{3} \cdot 9 \mathrm{H}_{2} \mathrm{O}\right)(\geq 98 \%)$ of Sigma Aldrich; $\mathrm{C}_{6} \mathrm{H}_{8} \mathrm{O}_{7}$ and $\mathrm{NH}_{4} \mathrm{OH}$ of Karal®, Sorghum bicolor seeds (Agricola "Don Luis") were purchased from local distributor.

Seeds were cleaned with $2 \%$ sodium hypochlorite solution and washed with distilled water. After cleaning the seeds were immersed in $70 \%$ ethanol solution. Bacteriological agar (BA) has been used as growth medium having concentration $7 \mathrm{~g} \mathrm{~L}^{-1}$. Following MWCNT $\left(20 \mathrm{mg} \mathrm{L}^{-1}\right)$, NZF $\left(10\right.$ and $\left.100 \mu \mathrm{gL}^{-1}\right)$ and 
combination of both MWCNT (20 mgL $\mathrm{mL}^{-1}$ ) and NZF (10 and $\left.100 \mu \mathrm{gL}^{-1}\right)$ were used. 40 seeds of Sorghum bicolor L. were used in each treatment. Treatments were labelled according to their dose/concentration.

\section{Results \& Discussion:}

Structural and Morphological evaluation of $\mathrm{NZF}\left(\mathrm{ZnFe}_{2} \mathrm{O}_{4}\right)$ : NZF nanocrystals have been synthesized by citrate route method [5]. The X-ray diffraction pattern shows well defined peaks corresponding to the cubic spinel phase of $\mathrm{ZnFe}_{2} \mathrm{O}_{4}$ (JCPDS: 89-7412) (Figure-1a). The results suggest the presence of pure nanocrystalline zinc ferrite phase. The scanning electron microscopy (SEM) micrographs of NZF nanocrystal depicts smooth surface with irregular morphology showing the presence of agglomerates (Figure-1b). The Energy dispersive X-ray spectroscopic measurement (Figure-1c) confirms the elemental composition with tiny impurity of Carbon atoms.

Seed Germination and Statistical data Evaluation: Seeds were kept in a dark room with temperature $22-24{ }^{\circ} \mathrm{C}$ following germination and growth has been monitored for 10 days. Length, fresh weight and dry weight (FW and DW) were measured (Figure-2). ANOVA was done for observing significant difference, and Fisher's LSD test was performed in treatments that have p-value less than $\alpha(0.05)$.

The experiments were conducted during the germination stage. The FW and DW were taken to analyses the water availability and biomass of seedlings with/without use of nanomaterials. Individual use of MWCNT and NZF treatments promoted better shoot and root growth respectively, while the combination of MWCNTs and NZFs resulted in root and shoot growth. DW has been increased with the use of NZF $\left(100 \mu \mathrm{gL}^{-1}\right)$. NZF at higher concentration helped to increase the biomass of shoot. Thus, in conclusion the carbon nanotubes and nano-ferrites in adequate concentration can help to enhance the growth via water and mineral uptakes providing a suitable and favorable condition for root, shoot growth and biomass gain in Sorghum plants.

Acknowledgment: Authors are highly grateful for the CONACYT Basic Science project (A1-S-47641). 

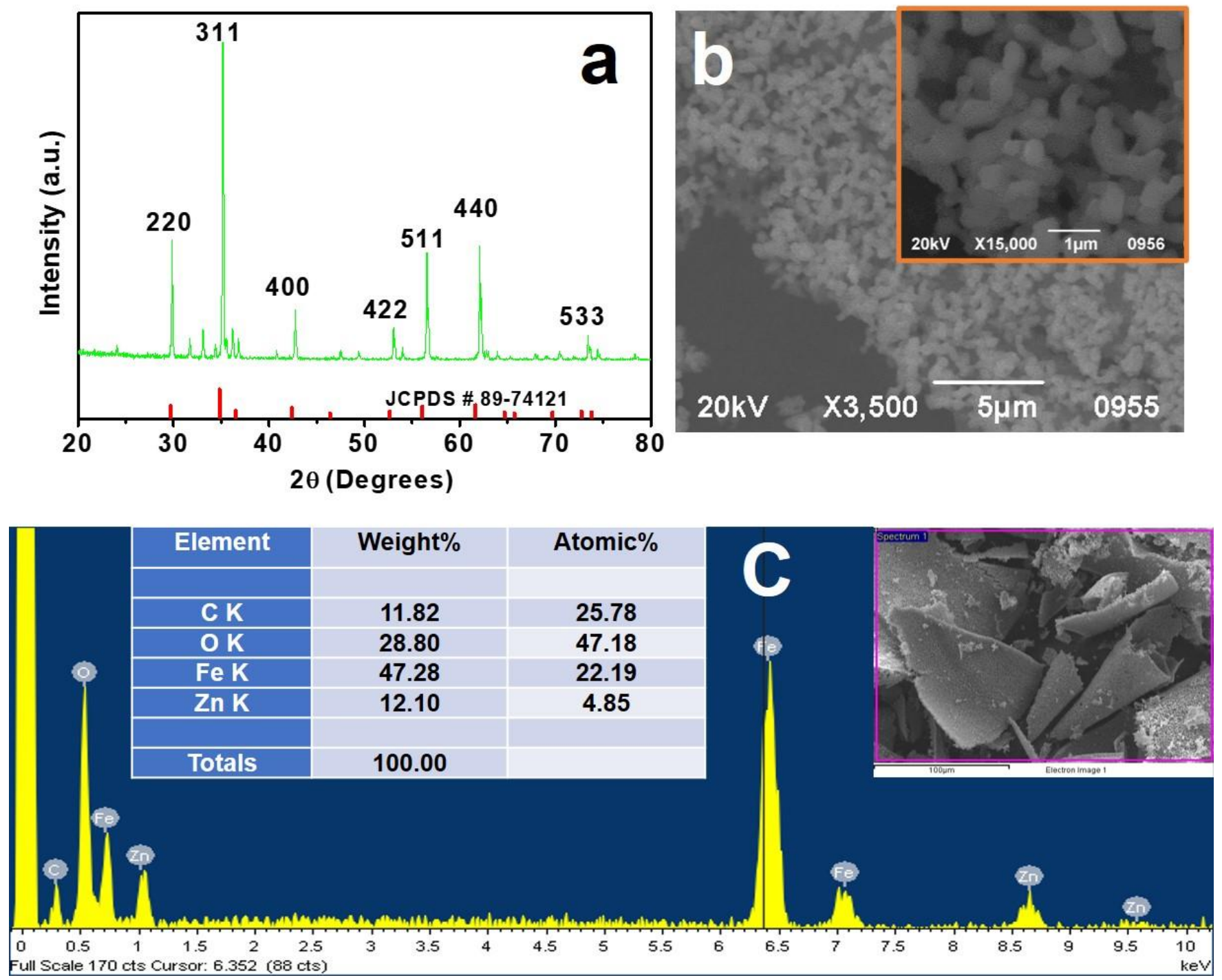

Figure 1. Figure 1. Structural and morphological characterization of ZnFe2O4 (NZF) nanocrystals. a) Xray diffraction patterns of $\mathrm{ZnFe} 2 \mathrm{O} 4$ (NZF) nanocrystals. b) Scanning electron microscopy (SEM) micrographs of ZnFe2O4 (NZF) nanocrystals. Inset present the SEM micrograph at higher magnification. C) Energy dispersive X-ray spectroscopic measurement of whole analyzed area and their energy spectrum. 

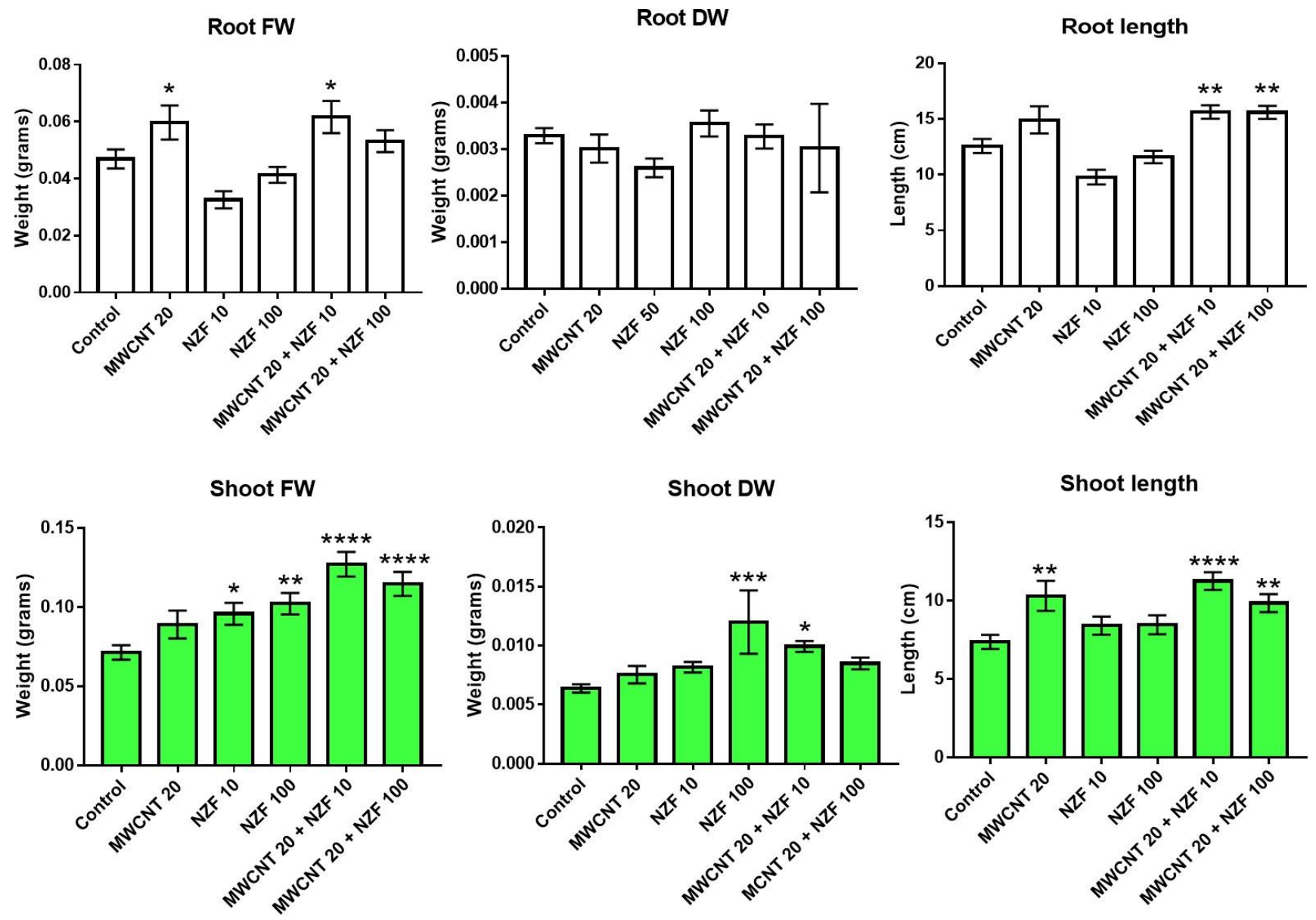

Figure 2. Figure-2: Effect of applied nanomaterials in different physiological parameters during germination/Growth of Shorghum.

\section{References}

[1] United States Department of Agriculture- Natural Resources Conservation Services. Plant guide for sorghum (Sorghum bicolor L.), (2015). https://plants.usda.gov/java/.

[2] D. K. Tiwari, N. Dasgupta-Schubert, L. M. Villasenor, D. Tripathi, and J. Villegas. "Interaction of carbon nanotubes with mineral nutrients for the promotion of growth of tomato seedlings." Nano Studies 7 (2013): 87-96.

[3] M. V. Khodakovskaya, Kanishka De Silva, Alexandru S. Biris, EnkeledaDervishi, and Hector Villagarcia. "Carbon nanotubes induce growth enhancement of tobacco cells." ACS nano 6, no. 3 (2012): 2128-2135.

[4] D. K. Tiwari, N. Dasgupta-Schubert, LM VillaseñorCendejas, J. Villegas, L. Carreto Montoya, and SE Borjas García. "Interfacing carbon nanotubes (CNT) with plants: enhancement of growth, water and ionic nutrient uptake in maize (Zea mays) and implications for nanoagriculture." Applied Nanoscience 4, no. 5 (2014): 577-591.

[5] D. K. Tiwari, S. E. Almanza-Morales, L. M. Morales-Villagómez, M. O. Alonso-Pérez, Prakhar Sengar, J. Estudillo-Ayala, and D. HomeroGalván. "Tailoring the structural and magnetic property of nanocrystalline $\mathrm{Mn} \times \mathrm{Zn} \mathrm{1-x}$ Fe 204 synthesized by citrate route method." MRS Advances 2, no. 49 (2017): 2763-2768. 